\title{
COMPaRATIVE EFFICACY ON DOGS OF A SINGLE TOPICAL TREATMENT WITH THE PIONEER FIPRONIL/(S)-METHOPRENE AND AN ORAL TREATMENT WITH SPINOSAD AgAINST CTENOCEPHALIDES FELIS
}

\author{
BEUGNET F.*, DOYLE V.**, MURRAY M.*** \& CHALVET-MONFRAY K.*****
}

\section{Summary:}

In the study reported here, the pioneer fipronil/(S)-methoprene topical product (FRONTLINE ${ }^{\circledR}$ PLUS, Merial Limited, Duluth, GA) was compared to the oral spinosad product (COMFORTIS ${ }^{\circledR}$ Elanco, Greenfield, IN) for efficacy against adult fleas and preventing egg production. The product presentations, doses and labelling were the one applicable in the USA. Using a standard protocol, 200 cat fleas of mixed sex were applied to dogs on Days 1,7 , $14,21,28,35$, and 42. Dogs were combed to remove fleas 24 hours post-infestation, the fleas were counted, collected, and then reapplied to each dog following completion of their respective count. At 48 hours post-infestation, comb counts were performed and fleas were removed. No fleas were collected from any dog in the fipronil/(S)-methoprene group at any 24 or 48 hours postinfestation assessment throughout the six weeks study, yielding a preventive efficacy of $100 \%$. For the spinosad treatment, efficacy was $100 \%$ at 24 hours and 48 hours through Day 16, and thereafter declined. The results observed in the spinosad-treated dogs were highly variable between animals. At the 24 and 48 hours counts following the Day 21 infestation, only five of eight spinosad-treated dogs (62.5\%) were flea-free. Following the Day 28 infestation, spinosad efficacy fell to $85 \%$ and $89 \%$, for the 24 hours and 48 hours counts, and only two dogs (25\%) were flea free, compared to $100 \%$ flea-free dogs in the fipronil/(S)methoprene group. No fleas were collected from the fipronil/(S)methoprene treated dogs throughout the entire study, therefore, no eggs were collected at any time from any dog in the group. However, in the spinosad group adult fleas were found on dogs starting on Day 21 and by Day 30, 42 eggs were collected from one dog that had 107 adult fleas counted at 48 hours. At Day 37 and Day 49, more than 100 eggs were collected from each dog in the spinosad-treated and control groups.

KEY WORDS: fipronil/(S)-methoprene, spinosad, Ctenocephalides felis felis, duration of efficacy, flea egg, FRONTLINE ${ }^{\circledR}$ PLUS, COMFORTIS ${ }^{\circledR}$.

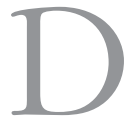
ogs are infested by two flea species: the cat flea, Ctenocephalides felis felis, which is considered to be the predominant flea species found on dogs and cats worldwide (Durden

\footnotetext{
* Merial S.A.S., 29, avenue Tony Garnier, 69007 Lyon, France.

** Charles River Laboratories Preclinical Services Ireland Ltd, Carrentrila, Ballina, Co. Mayo, Ireland.

**** Merial Limited, 3239 Satellite Bvd, Duluth, GA30096, USA.

***:* Biomathematics Unit, Veterinary Faculty, 1, avenue Bourgelat, 69280 Marcy L’Étoile, France.

Correspondence: Frédéric Beugnet.

E-mail: frederic.beugnet@merial.com
}

Résumé : COMPARAISON DE L'EFFICACITÉ DU TOPIQUE À BASE DE FIPRONIL/S)-MÉTHOPRĖNE À CELLE DU TRAITEMENT ORAL PAR SPINOSAD CONTRE CTENOCEPHALIDES FELIS CHEZ LE CHIEN

Dans l'étude ici présentée, le produit topique princeps à base de fipronil/(S)méthoprène (FRONTLINE ${ }^{\circledR}$ PLUS, Merial Limited, Duluth, $\mathrm{GA}$ ) a été comparé au produit oral à base de spinosad (COMFORTIS ${ }^{\circledR}$ Elanco, Greenfield, IN) en ce qui concerne l'efficacité anti-puces et la prévention de la production d'œufs de puces. Les présentations, dosages et notices d'utilisation qui ont été suivies sont celles de ces produits commercialisés aux États-Unis. Utilisant un protocole classique, 200 puces adultes mâles et femelles ont été déposées sur des chiens aux jours $0,7,14,21,28,35$ et 42. Les chiens ont été peignés pour collecter les puces 24 heures après chaque infestation. Ces dernières ont été comptées puis ont été redéposées sur les chiens. 48 heures après chaque infestation, les chiens ont été de nouveau peignés et les puces collectées définitivement. Aucune puce n'a été récupérée sur aucun des chiens traité par le fipronil/(S)-méthoprène à 24 heures ou 48 heures après infestation pendant les six semaines de l'étude, d'où une efficacité préventive de $100 \%$. En ce qui concerne le groupe traité par le spinosad, l'efficacité préventive a été de $100 \%$ à 24 et 48 heures jusqu'au jour 16, et a ensuite diminué. Les résultats ont été très variables selon les chiens dans ce groupe. À 24 et 48 heures après l'infestation du jour 21, seulement cinq des huit chiens (62,5\%) n'avaient pas de puces. Après l'infestation du jour 28, l'efficacité moyenne tombait à $85 \%$ à 24 heures et $89 \%$ à 48 heures, et seulement deux chiens sur huit (25\%) n'avaient pas de puces, contre $100 \%$ dans le groupe traité fipronil/(S)-méthoprène. Aucun œuf de puces n'a été collecté durant les six semaines de l'étude sur les chiens du groupe traité par le fipronil/(S)-méthoprène. Dans le groupe traité par le spinosad, des puces adultes sont observées sur les chiens après l'infestation du jour 21, et au jour 30, 42 œufs ont été récupérés sur un chien qui avait 107 puces comptées à 48 heures. Aux jours 37 et 49, plus de 100 œufs de puces ont été collectés sur une période de 12 heures sur chaque chien du groupe spinosad, ainsi que sur tous les chiens du groupe contrôle.

MOTS-CLÉS : fipronil/(S)-méthoprène, spinosad, Ctenocephalides felis felis, rémanence, œuf de puce, FRONTLINE ${ }^{\circledR}$ PLUS, COMFORTIS ${ }^{\circledR}$.

et al., 2005; Farkas et al., 2009; Gracia et al., 2007), and the dog flea, Ctenocephalides canis, generally regarded as less important (Beck et al., 2006; Dryden \& Rust, 1994; Franc et al., 1998). Fleas are responsible for various clinical signs, including pruritus, alopecia, anaemia, seborrhoea, and development of an allergies (Flea Allergy Dermatitis). Fleas are also the carrier of pathogens, including Rickettsia felis, Bartonella benselae, and Mycoplasma-Haemoplasma and the parasite, Dipylidium caninum. Due to their low host-specificity, fleas easily infest numerous species of wild animals, feral dogs and cats, pets 
and will feed on pet owners. The goals of effective flea control are to provide relief to the pet and eliminate infestation of the premises (Dryden, 2009). Controlling flea infestations is mainly based on the regular administration of flea adulticides on pets, and the use of insect growth regulators (IGR) (Franc \& Cadiergues, 1995; Jacobs et al., 2001). Available insecticides are represented by many classes with various modes of action (IRAC, 2010). The majority of available treatments for dogs and/or cats are topical spot-on applications (Barnett et al., 2008; Cadiergues et al., 2001; Rust et al., 2007; Young et al., 2004). The active molecules of these topical preparations are absorbed and act systemically, or spread on the skin and act by direct contact with the arthropods (Cochet et al., 1997). A few products are given orally like lufenuron, nitenpyram, and more recently spinosad (Dobson et al., 2000; Kirst, 2010; Robertson-Plouch et al., 2008).

The most effective animal-based flea control strategies need to provide: 1 - a sustained activity and speed of kill on adult fleas during a known period (at least a month); and 2 - the control of immature stages by inhibiting the production of eggs and/or the development of flea eggs into larvae, pupae and newly emerged fleas (Dryden, 2009; Dryden et al., 2000; Beugnet \& Franc, 2010). Failure to kill all fleas before they can reproduce in the absence of an insect growth regulator can permit the persistence of a premise flea infestation.

The aim of this trial was to study and compare the level and duration of efficacy of the topical formulation of fipronil/(S)-methoprene (FRONTLINE ${ }^{\circledR}$ PLUS, Merial Limited, Duluth, GA) and the oral formulation of spinosad (COMFORTIS ${ }^{\circledast}$ Elanco, Greenfield, IN) against adult fleas on dogs, and to assess their respective efficacy for controlling flea egg production. Fipronil is a phenylpyrazole acting by contact on arthropods, binding and blocking GABA and glutamategated chloride channels on the arthropod nerve cells and inducing the parasite death. Spinosad is a mixture of spinosyns $\mathrm{A}$ and $\mathrm{D}$, belonging to the spinosyn macrocyclic lactone group, and acting on insects through ingestion by stimulating the nicotinic acetylcholine receptors of insect nerve cells.

\section{MATERIALS AND METHODS}

\section{StUdy Design}

T This study was a negative controlled efficacy study using a randomized block design where blocks were based on pre-treatment flea counts. Three groups of eight dogs were formed: untreated control, fipronil/(S)-methoprene treated group and spinosad treated group. 30 healthy Beagle dogs were used, 15 males and 15 females, between eight to 12 months old. To qualify for inclusion, dogs could not have been treated with an ectoparasiticide within three months prior to the start of the study. Animals were managed similarly and with due regard for their well-being. Animals were handled in compliance with the relevant Institutional Animal Care and Use Committee approvals and any other, e.g. national or local, applicable regulations and requirements.

All dogs were shampooed, according to the Schedule of Operations, with a non-insecticidal shampoo for approximately five minutes each prior to or on Day -20. Dogs were pre-infested with 200 ( \pm 5) adult unfed C. felis once, on Day -16, for selection purposes. Three dogs of each sex with lowest flea counts were removed. Dogs were treated on Day 0, and post treatment, infestations were performed on Days $1,7,14,21,28,35$, and 42 using $200( \pm 5)$ adult unfed C. felis, and counts were performed at 24 and 48 hours post-infestation.

Adult unfed C. felis belonging to the CRL strain (Charles River Laboratories, Ireland) were used for infestations. These fleas are not known to be tolerant to any ectoparasiticide. The study was conducted such that all personnel involved in parasite infestation counting and evaluation of results were blinded to the treatment.

\section{TREATMENT ADMINISTRATION (Table I)}

Dogs were weighed between Day -3 and Day -1 for dosage determinations. When the weights were not a whole $\mathrm{kg}$, they were rounded up to the next whole $\mathrm{kg}$. Dogs in Treatment Group 1, negative control, were untreated.

\begin{tabular}{|c|c|c|c|c|}
\hline & Bodyweight range - kg (lbs) & Pipette size & Pipette volumes - mL & Tablet size - mg \\
\hline \multirow[t]{2}{*}{ Frontline ${ }^{\circledR}$ Plus treated dogs } & Up to $10(22 \mathrm{lbs})$ & S & 0.67 & \\
\hline & $10.1-20(23-44 \mathrm{lbs})$ & M & 1.34 & \\
\hline Comfortis ${ }^{\circledR}$ treated dogs & 9.1-18.1 (20.1-40 lbs) & & & 560 \\
\hline
\end{tabular}

Table I. - Dosage of dogs in the treated groups. 
Dogs in Treatment Group 2 were treated with the appropriate pipette size of FRONTLINE ${ }^{\circledR}$ PLUS spoton. For treatment administration, the total volume was applied on one spot placed on the midline of the neck. The hair was parted at the base of the neck, between the shoulder blades, until the skin was visible. The tip of the pipette was placed on the skin and squeezed to empty its contents directly onto the skin. The dogs treated with FRONTLINE $^{\circledR}$ PLUS weighed from 10 to $13.3 \mathrm{~kg}$. They were all treated with the $1.34 \mathrm{~mL}$ pipette except the $10 \mathrm{~kg}$ dog with the $0.67 \mathrm{~mL}$ pipette.

Dogs in Treatment Group 3 were treated with the appropriate chewable tablet of COMFORTIS ${ }^{\circledR}$, using the US presentations and labeling. The tablet was administered with food as recommended by the manufacturer. Following treatment on Day 0, all dogs were observed hourly ( \pm 30 minutes) for four hours after the last animal was treated. The dogs treated with COMFORTIS $^{\circledR}$ weighed from 10.4 to $15.8 \mathrm{~kg}$. They were all treated with the $560 \mathrm{mg}$ tablet. The minimal treatment dose is $30 \mathrm{mg} / \mathrm{kg}$ in the USA and $45 \mathrm{mg} / \mathrm{kg}$ in Europe. Except two dogs treated at $35.44 \mathrm{mg} / \mathrm{kg}$ and $38.55 \mathrm{mg} / \mathrm{kg}$, all the others received a dose over the minimum European recommended dose of $45 \mathrm{mg} / \mathrm{kg}$.

\section{SPECIFICATION OF STUDY VARIABLES}

\section{- Adult flea count}

Fleas were comb-counted initially at 24 hours postinfestation, then replaced on the $\mathrm{dog}$, and then counted and removed at 48 hours post-infestation on all dogs.

\section{- Egg count}

Flea eggs were collected overnight for a 12 hours period from 36 to 48 hours post infestation. The dogs were place in a cage with a grille at the bottom and a dark plate below the grille. The flea eggs are small, oval and white, measuring $0.4 \times 0.6 \mathrm{~mm}$. When the 24 hours adult flea counts were found to be positive, those dogs were subsequently placed in cages for flea egg collection. It was predetermined that egg counts at or higher than 100 eggs per dog within a 12 hours period would be sufficient enough to ensure the animal's environment would be continuously contaminated. Egg totals less than 100 were recorded, but when the egg counts reached or exceeded the threshold of 100 flea eggs within a 12 hours period, the count was entered as a maximum of 100 eggs.

\section{DATA ANALYSIS}

- Adulticidal efficacy

Counts of live adult fleas were transformed to the natural logarithm of (count +1$)$ for calculation of geo- metric means by treatment group at each time point. Percent reduction from the negative control mean was calculated using the formula $[(\mathrm{C}-\mathrm{T}) / \mathrm{C}] \times 100$, where $\mathrm{C}=$ geometric mean for the control group and $\mathrm{T}=$ geometric mean for the treated group. Arithmetic means were also calculated.

- Statistical analysis

The three treatment groups were initially tested using the Kruskal-Wallis rank sum test. Because all KruskalWallis rank tests were significant, a non parametric multiple comparison test (Pairwise Wilcoxon Rank Sum Test) was done at each date. Thus for each date, the test compared Control vs FRONTLINE $^{\circledR}$ PLUS, Control vs COMFORTIS $^{\circledR}$, and COMFORTIS ${ }^{\circledR}$ vs FRONTLINE $^{\circledR}$ PLUS.

\section{RESULTS}

\section{ADUlTICIDAL EFFICACY (Tables II and III)}

To fleas were collected in the fipronil/(S)methoprene treated group on any dog at any 1 time during the six weeks of the trial. The preventive efficacy was $100 \%$, and all dogs remained free of fleas (Tables II and III).

In the group treated with spinosad, efficacy was $100 \%$ during the first two weeks (from Day 1 to Day 14 challenge), but for the Day 28 infestation efficacy fell to $85 \%$ at the 24 hours count and to $89 \%$ at the 48 hours count (Table III, Fig. 1). The geometric and arithmetic means were significantly different between the spinosad and the fipronil/(S)-methoprene groups following the weekly infestations on Day 28, Day 35 and Day 42 at both 24 hours and 48 hours ( $p<0.01$ at each time counts). There was no significant difference between the spinosad group and the untreated control group at the 48 hours count following the Day 42 infestation.

Moreover, the results in the spinosad treated group were highly variable between dogs (Table II; Figs 2 and 3). Following the Day 21 infestation, only 5/8 $(62.5 \%)$ dogs remained free of fleas at 24 and 48 hours in the spinosad group, and only 2/8 (25\%) of them were still free of fleas following the Day 28 infestation.

\section{EGG COLLECTIONS (Table IV)}

No eggs were collected from the fipronil/(S)-methoprene group at any time on any dog. A single application of the fipronil/(S)-methoprene topical controlled all flea stages during the entire six weeks. For the infested dogs that produced flea eggs, eggs were randomly collected until a target number of 100 


\begin{tabular}{|c|c|c|c|c|c|c|c|c|c|}
\hline Groups & Dog tag number & Day $22^{* *}$ & Day 23 & Day 29 & Day 30 & Day 36 & Day 37 & Day 43 & Day 44 \\
\hline \multirow[t]{8}{*}{ Untreated } & 58091 & 133 & 124 & 149 & 127 & 128 & 135 & 137 & 126 \\
\hline & 27351 & 125 & 103 & 71 & 87 & 119 & 126 & 147 & 155 \\
\hline & 40061 & 135 & 138 & 118 & 124 & 155 & 159 & 121 & 141 \\
\hline & 43861 & 156 & 164 & 132 & 114 & 107 & 141 & 150 & 132 \\
\hline & 22774 & 137 & 121 & 133 & 116 & 118 & 106 & 138 & 133 \\
\hline & 39545 & 117 & 111 & 104 & 106 & 111 & 123 & 152 & 143 \\
\hline & 94289 & 161 & 123 & 132 & 130 & 142 & 128 & 153 & 147 \\
\hline & 28632 & 133 & 154 & 102 & 102 & 141 & 132 & 136 & 144 \\
\hline \multirow[t]{9}{*}{ Frontline ${ }^{\circledR}$ Plus } & 38603 & 0 & 0 & 0 & 0 & 0 & 0 & 0 & 0 \\
\hline & 38793 & 0 & 0 & 0 & 0 & 0 & 0 & 0 & 0 \\
\hline & 35092 & 0 & 0 & 0 & 0 & 0 & 0 & 0 & 0 \\
\hline & 67804 & 0 & 0 & 0 & 0 & 0 & 0 & 0 & 0 \\
\hline & 13789 & 0 & 0 & 0 & 0 & 0 & 0 & 0 & 0 \\
\hline & 42356 & 0 & 0 & 0 & 0 & 0 & 0 & 0 & 0 \\
\hline & 38257 & 0 & 0 & 0 & 0 & 0 & 0 & 0 & 0 \\
\hline & 37299 & 0 & 0 & 0 & 0 & 0 & 0 & 0 & 0 \\
\hline & \% Flea free dogs & $100 \% *$ & $100 \% *$ & $100 \% *$ & $100 \% *$ & $100 \% *$ & $100 \% *$ & $100 \% *$ & $100 \% *$ \\
\hline \multirow[t]{9}{*}{ Comfortis $^{\circledR}$} & 89565 & 0 & 0 & 0 & 0 & 59 & 48 & 118 & 112 \\
\hline & 41363 & 13 & 11 & 87 & 79 & 75 & 89 & 180 & 179 \\
\hline & 33824 & 0 & 0 & 0 & 0 & 74 & 67 & 94 & 77 \\
\hline & 02777 & 0 & 0 & 32 & 22 & 90 & 73 & 127 & 125 \\
\hline & 44355 & 17 & 6 & 57 & 56 & 116 & 113 & 105 & 107 \\
\hline & 44259 & 0 & 0 & 19 & 3 & 0 & 0 & 122 & 112 \\
\hline & 42352 & 0 & 0 & 31 & 22 & 23 & 42 & 134 & 141 \\
\hline & 27347 & 48 & 15 & 115 & 107 & 106 & 104 & 125 & 168 \\
\hline & $\%$ Flea free dogs & $62.5 \% *$ & $62.5 \% *$ & $25 \% *$ & $25 \% *$ & $12.5 \% *$ & $12.5 \% *$ & $0 \% *$ & $0 \% *$ \\
\hline
\end{tabular}

* Significant difference between the two treatment groups at all time points after Day 21 infestation at $\mathrm{p}<0.05$.

** Table starting at Day 22 because no fleas were counted in any of the treated group the weeks before.

Table II. - Number of fleas counted at 24 hours and 48 hours post-infestation, from Day 21 infestation to Day 42 infestation. Calculation of the $\%$ of flea free dogs and comparison between the two treated groups.

\begin{tabular}{llccccccc}
\hline & & Day 2 & Day 8 & Day 15 & Day 22 & Day 29 & Day 36 & Day 43 \\
\hline \% Efficacy at 24 hours counts & Frontline $^{\circledR}$ Plus & 100 & 100 & 100 & 100 & 100 & 100 & 100,0 \\
& Comfortis $^{\circledR}$ & 100 & 100 & 100 & 98.4 & $85.0^{*}$ & $67.8^{*}$ & $12.6^{*}$ \\
\hline \% Efficacy at 48 hours counts & Frontline $^{\circledR}$ Plus & 100 & 100 & 100 & 100 & 100 & 100 & 100,0 \\
& Comfortis $^{\circledR}$ & 100 & 100 & 100 & 98.9 & $89.0^{*}$ & $67.9^{*}$ & $11.5^{*}$ \\
\hline
\end{tabular}

* Significant difference between the two treatment groups at Day 29, Day 36 and Day 43 at $\mathrm{p}<0.01$.

Table III. - Compared killing efficacies of the two treatments on adult fleas at 24 and 48 hours counts.

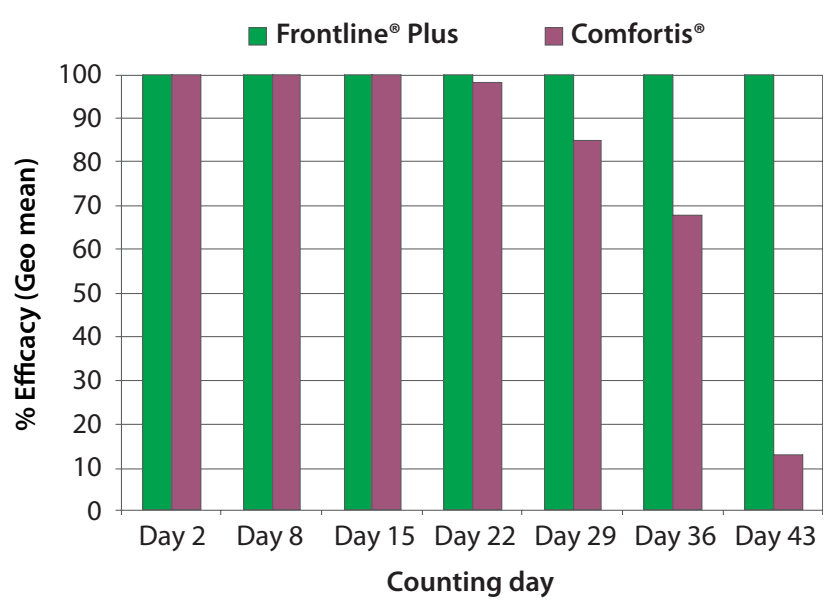

Fig 1. - Comparative $\%$ of adult flea efficacy in the two treated groups at 24 hours counts.

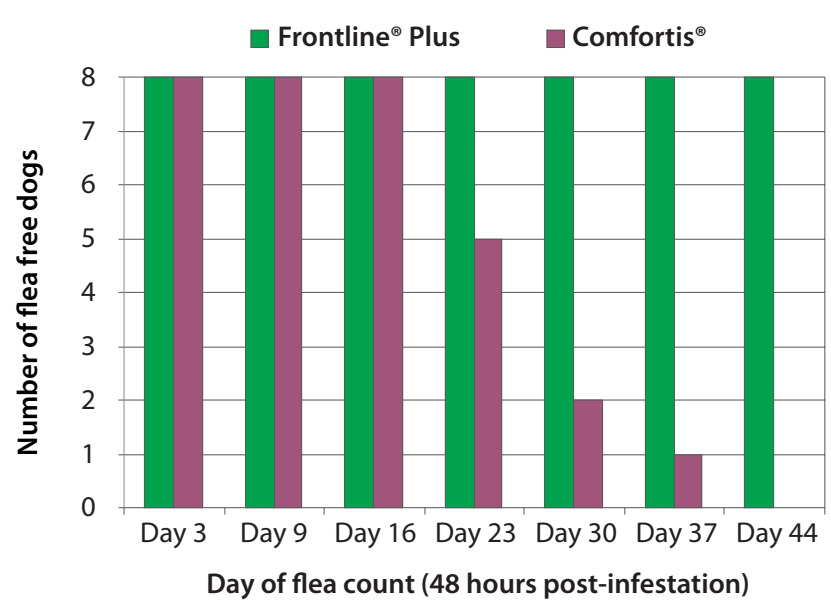

Fig 2. - Comparative number of flea free dogs in the two treated groups at 48 hours counts. 


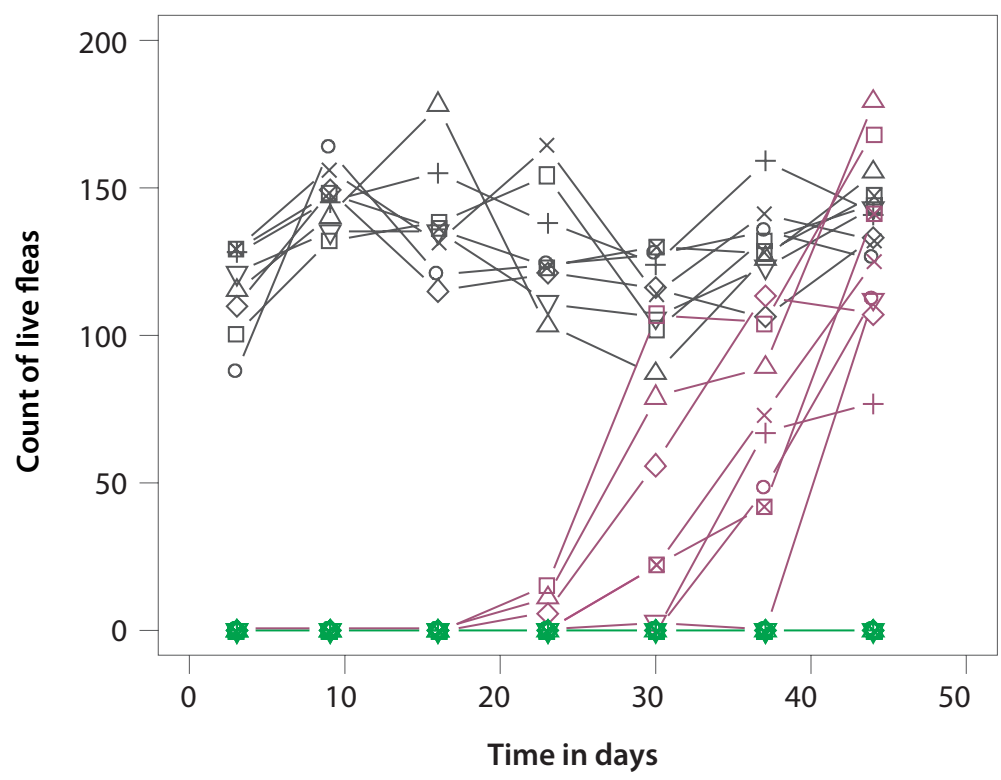

All dogs from the control group

All dogs from the Comfortis ${ }^{\circledR}$ treated group

All dogs from the Frontline ${ }^{\circledR}$ Plus treated group

Fig 3. - Distribution of the number of live fleas per each dog at each counting point.

One line represents the data observed in the same dog.

\begin{tabular}{|c|c|c|c|c|c|c|c|}
\hline \multirow[b]{2}{*}{ Groups } & \multirow[b]{2}{*}{ Dog tag number } & \multicolumn{6}{|c|}{ Number of eggs collected overnight with a threshold at 100 eggs/dog } \\
\hline & & Day 9 & Day 16 & Day 23 & Day 30 & Day 37 & Day 44 \\
\hline \multirow[t]{8}{*}{ Untreated } & 58091 & 100 & 100 & 100 & 100 & 100 & 100 \\
\hline & 27351 & 100 & 100 & 100 & 100 & 100 & 100 \\
\hline & 40061 & 100 & 100 & 100 & 100 & 100 & 100 \\
\hline & 43861 & 100 & 100 & 100 & 100 & 100 & 100 \\
\hline & 22774 & 100 & 100 & 100 & 100 & 100 & 100 \\
\hline & 39545 & 100 & 100 & 100 & 100 & 100 & 100 \\
\hline & 94289 & 100 & 100 & 100 & 100 & 100 & 100 \\
\hline & 28632 & 100 & 100 & 100 & 100 & 100 & 100 \\
\hline \multirow[t]{8}{*}{ Frontline ${ }^{\circledR}$ Plus } & 38603 & 0 & 0 & 0 & 0 & 0 & 0 \\
\hline & 38793 & 0 & 0 & 0 & 0 & 0 & 0 \\
\hline & 35092 & 0 & 0 & 0 & 0 & 0 & 0 \\
\hline & 67804 & 0 & 0 & 0 & 0 & 0 & 0 \\
\hline & 13789 & 0 & 0 & 0 & 0 & 0 & 0 \\
\hline & 42356 & 0 & 0 & 0 & 0 & 0 & 0 \\
\hline & 38257 & 0 & 0 & 0 & 0 & 0 & 0 \\
\hline & 37299 & 0 & 0 & 0 & 0 & 0 & 0 \\
\hline \multirow[t]{8}{*}{ Comfortis $^{\circledR}$} & 89565 & 0 & 0 & 0 & 0 & 100 & 100 \\
\hline & 41363 & 0 & 0 & 0 & 0 & 100 & 100 \\
\hline & 33824 & 0 & 0 & 0 & 0 & 100 & 100 \\
\hline & 02777 & 0 & 0 & 0 & 0 & 100 & 100 \\
\hline & 43355 & 0 & 0 & 0 & 0 & 100 & 100 \\
\hline & 44259 & 0 & 0 & 0 & 0 & 80 & 100 \\
\hline & 42352 & 0 & 0 & 0 & 0 & 100 & 100 \\
\hline & 27347 & 0 & 0 & 0 & 42 & 100 & 100 \\
\hline
\end{tabular}

Table IV. - Number of egg collections overnight per each dog from Day 9 to Day 44.

per each dog. In the control group, 100 eggs were collected from each dog at every collect time.

In the spinosad group, 42 eggs were collected from one dog following the Day 28 infestation. That same dog had 107 adult fleas counted at 48 hours. Following the Day 35 and Day 42 infestations, the maximum threshold of 100 eggs collected was exceeded on all dogs in the spinosad treated group.

\section{DISCUSSION}

This well controlled study confirmed both the high efficacy and the long duration of efficacy of the pioneer fipronil/(S)-methoprene (FRONTLINE $^{\circledR}$ COMBO/FRONTLINE ${ }^{\circledR}$ PLUS, Merial Limited, Duluth, GA) topical formulation on dogs with at least six weeks of $100 \%$ efficacy. Similar 
results were previously obtained in other trials on both dogs and cats (Cadiergues et al., 2001; Franc et al., 2007; Schenker et al., 2003; Young et al., 2004). The results of this study and those of previous studies also demonstrate the consistency of control provided by this formulation from one dog to the next. Due to the high level of efficacy and speed of kill of the fipronil, no eggs were collected on the dogs at any time of the study. It was previously shown that if any newly acquired fleas survive long enough to produce eggs, the eggs laid would be sterilized by (S)-methoprene (Young et al., 2004).

In this study, the treatment with spinosad provided complete flea control for only 16 days after treatment. After the D21 infestation, only five of the eight $(62.5 \%)$ spinosad-treated dogs were flea-free at both the 24 hours and 48 hours counts, and after the Day 28 infestation only two of the eight dogs (25\%) remained flea-free at both the 24 hours and 48 hours counts.

Every effort was made in the study design to ensure consistency of the animals; dogs were selected from the same breed, same age and similar weight ranges and were maintained under essentially identical management conditions for assessments, feeding, watering and handling. The consistency of the flea burdens observed on the control dogs attests to both the consistency of animals and management practices.

The variable and declining flea-killing efficacy of orally administered spinosad were observed in other post-approval laboratory studies. In one report (Blagburn et al., 2010), efficacy studies using the oral spinosad formulation were conducted at research laboratories in the United States and in Ireland, with each site using its own flea strain. Purpose-bred Beagle dogs that were 14 to 16 weeks old were used. Data combined from the three study sites revealed that 48 hours pulicidal efficacies for oral spinosad were $100 \%$ through Day 9, thereafter declining to $85 \%$ (Day 16), $63 \%$ (Day 23), and $2 \%$ (Day 30). There were no statistical differences $(p>0.05)$ in the number of live fleas recovered from the dogs treated with oral spinosad compared to untreated control dogs on study Days 22 and 29 for two study sites and on Day 29 for the third site.

In a study conducted at another research laboratory, purpose-bred mongrel dogs that were eight to 11 months old were used, and they were treated with oral spinosad on Day 0 according to label directions (Dryden et al., 2010). 100 cat fleas of the KS1 flea strain were applied to each dog on Days -2, 7, 14, 21, and 28 after treatment, and the fleas were removed with a flea comb six and 24 hours post- infestation. Oral spinosad provided at least 93.9\% efficacy at six hours post-infestation through Day 14 , dropping to $54.9 \%$ efficacy on Day 21 and $35 \%$ on Day 28. Efficacy on Day 29 (24 hours post-infestation) was $22 \%$, and the geometric mean flea counts on treated dogs were not statistically different from untreated controls.

The unpredictably variable efficacy provided by oral spinosad after 16 days post-treatment may be due to different absorption, metabolism and elimination kinetics between dogs. Orally administered spinosad acts by the systemic route after absorption from the gastrointestinal tract (Kirst, 2010). Data from the Comfortis Food and Drug Agency (FDA) Freedom of Information (FOI) summary showed a variable rate of elimination of spinosyns A and D between groups of dogs that had been administered technical grade spinosad in gelatin capsules. In a small group of dogs in which the elimination half-life was $6.8+/-3$ hours, 48 hours pulicidal efficacy on Day 30 was $89.1 \%$, compared to 48 hours efficacy of $97.8 \%$ in dogs with slower elimination (10.6+/- 3.7 hours) of spinosyns $\mathrm{A}$ and D. It was also shown that administration of oral spinosad without food markedly reduced peak plasma levels.

Orally administered spinosad can provide rapid speed of kill against existing flea infestations (Blagburn et al., 2010), but if efficacy is not maintained for the monthly application period, or longer if a pet owner is late in re-administering product, surviving fleas can lay eggs and perpetuate an environmental infestation (Franc \& Boushira, 2009). In the study reported here the pioneer fipronil/(S)-methoprene topical product provided $100 \%$ flea killing efficacy 24 hours after infestation through six weeks after treatment. Other studies have demonstrated that (S)-methoprene can provide inhibition of flea egg/larvae survival well after the adulticidal efficacy of fipronil begins to decline, providing long-lasting protection against the establishment of new environmental flea infestations (Franc et al., 2007; Young et al., 2004).

This study confirmed that providing relief to a pet and eliminating infestation of a premise by a pet requires regular dosing with formulations providing consistent and sustained activity against both adult and developmental stages of fleas.

Note: FRONTLINE ${ }^{\circledast}$ is a registered trademark of Merial. All other marks are the property of their respective owners. 


\section{REFERENCES}

Barnett S., Luempert L., Schuele G., Quezada A., Strehlau G. \& DOHERTY P. Efficacy of pyriprole topical solution against the cat flea, Ctenocephalides felis, on dogs. Veterinary Therapeutics, 2008, 9, 4-14.

Beck W., Boch K., Mackensen H., Wiegand B. \& Pfister K. Qualitative and quantitative observations on the flea population dynamics of dogs and cats in several areas of Germany. Veterinary Parasitology, 2006, 137, 130-136.

BEUGNET F. \& FRANC M. Results of a European multicentric field efficacy study of fipronil-(S) methoprene combination on flea infestation of dogs and cats during 2009 summer. Parasite, 2010, 17, 337-342.

Blagburn B.L., Cruthers L., Ketzis J., Arther R., Davis W., Schroeder I., Settje T. \& Butler J.M. Comparative efficacy of Advantage ${ }^{\circledR}$ Topical solution (imidacloprid) and Comfortis ${ }^{\circledR}$ Chewable Tablets (spinosad) for the control of fleas on dogs. Proceedings AAVP, $55^{\text {th }}$ Annual Meeting, Atlanta, Georgia, 2010, p. 49.

Blagburn B.L., Young D.R., Moran C., Meyer J.A., LeighHeffron A., PaArlberg T., Zimmermann A.G., Mowrey D., WisEMAN S. \& SNYDE D.E. Effects of orally administered spinosad (Comfortis ${ }^{\circledR}$ ) in dogs on adult and immature stages of the cat flea (Ctenocephalides felis). Veterinary Parasitology, 2010, 168, 312-317.

Cadiergues M.C., Caubet C. \& Franc M. Comparison of the activity of selamectin, imidacloprid and fipronil for the treatment of dogs infested experimentally with Ctenocephalides canis and Ctenocephalides felis felis. Veterinary Record, 2001, 149, 704-706.

Cochet P., Birckel P., Bromet-Petit M., Bromet N. \& Weil A. Skin distribution of fipronil by microautoradiography following topical administration to the Beagle dog. European Journal of Drug Metabolism and Pharmacokinetics, 1997, 22, 211-216.

Dobson P., Tinembart O., Fisch R.D., Junquera P. Efficacy of nitenpyram as a systemic flea adulticide in dogs and cats. Veterinary Record, 2000, 147, 709-713.

DRYDEN M.W. Flea and tick control in the $21^{\text {st }}$ century: challenges and opportunities. Veterinary Dermatology, 2009, 20, 435-440.

Dryden M.W., Deneberg T.M. \& Bunch S. Control of fleas on naturally infested dogs and cats and in private residences with topical spot applications of fipronil or imidacloprid. Veterinary Parasitology, 2000, 93, 69-75.

Dryden M., Payne P., Smith V., McBride A. \& Ritchie D. Efficacy of topically applied dinotefuran formulations and orally administrered spinosad tablets against KS1 flea strain infesting dogs. Proceedings AAVP, 55 ${ }^{\text {th }}$ Annual Meeting, Atlanta, Georgia, 2010, p. 51.

Dryden M.W. \& Rust K.M. The cat flea: biology, ecology and control. Veterinary Parasitology, 1994, 52, 1-19.

Durden L.A., Judy T.N., Martin J.E. \& Spedding L.S. Fleas parasiting domestic dogs in Georgia, USA: species composition and seasonal abundance. Veterinary Parasitology, 2005, 130, 157-162.
Farkas R., Gyurkovszky M., Solymosi N. \& Beugnet F. Prevalence of flea infestation in dogs and cats in Hungary combined with a survey of owner awareness. Medical and Veterinary Entomology, 2009, 23, 187-194.

Franc M. \& Cadiergues M.C. Utilisation du lufénuron dans le contrôle des infestations du chien par Ctenocpehalides felis. Revue de Médecine Vétérinaire, 1995, 146, 481-484.

Franc M., Beugnet F. \& Vermot S. Efficacy of fipronil-(S)methoprene on fleas, flea egg collection, and flea egg development following transplantation of gravid fleas onto treated cats. Veterinary Therapeutics, 2007, 8 (4), 285-292.

FranC M. \& BOUHSIRA E. Evaluation of speed and duration of efficacy of spinosad tablets for treatment and control of Ctenocephalides canis (Siphonaptera: Pulicidae) infestations in dogs. Parasite, 2009, 16, 125-128.

Franc M., Choquart P. \& Cadiergues M.C. Répartition des espèces de puces rencontrées chez le chien en France. Revue de Médecine Vétérinaire, 1998, 149, 135-140.

Gracia M.J., Calvete C., Estrada R., Castillo J.A., Peribanez M.A. \& Lucientes J. Fleas parasiting domestic dogs in Spain. Veterinary Parasitology, 2007, 151, 312-319.

IRAC - Insecticide Resistance ACtion CommitTeE. IRAC MoA (Mode of Action) classification Scheme, September 2010. www.irac-online.org.

Jacobs D.E., Hutchinson M.J. \& Ryan W.G. Control of flea populations in a simulated home environment model using lufenuron, imidacloprid or fipronil. Medical and Veterinary Entomology, 2001, 25, 73-77.

KIRST H.A. The spinosyn family of insecticides: realizing the potential of natural products research. The journal of antibiotics, 2010, 63, 101-111.

Robertson-Plouch C., Baker K.A., Hozak R.R., Zimmermann A.G. \& PARKS S.C. Clinical field study of the safety and efficacy of spinosad chewable tablets for controlling fleas on dogs. Veterinary Therapeutics, 2008, 9, 26-36.

Rust M.K., Rugg D. \& Rock D. Metaflumizone: a novel insecticide for application in animal health. Veterinary Parasitology (Special Edition), 2007, 150 (3), 175-281.

Schenker R., Tinembart O., Hubert-Droz E., Cavaliero T. \& YERLY B. Comparative speed of kill between nitenpyram, fipronil, imidacloprid, selamectin and cythioate against adult Ctenocephalides felis (Bouché) on cats and dogs. Veterinary Parasitology, 2003, 112, 249-254.

Young D.R., JEANNIN P.C. \& BoECKH A. Efficacy of fipronil/(S)methoprene combination spot on for dogs against shed eggs, emerging and existing adult cat fleas (Ctenocephalides felis, Bouché). Veterinary Parasitology, 2004, 125, 397-407.

Received on June $24^{\text {th }}, 2011$ Accepted on July $7^{\text {th }}, 2011$ 